\title{
Hayek, Campos e a Defesa do Autoritarismo*
}

\section{Hayek, Campos, and the Defense of Authoritarianism}

Henrique Nemeth Junior ${ }^{\text {a }}$

Eduardo Angeli ${ }^{a}$

\begin{abstract}
Resumo: O objetivo do presente trabalho é contribuir com o estudo do pensamento de Roberto Campos, em particular no que diz respeito a sua defesa de regimes autoritários, especialmente a ditadura militar brasileira. A hipótese do trabalho é que a sutil mudança na argumentação que Campos apresentava a respeito do golpe de 1964 pode ser relacionada à aproximação do brasileiro com o pensamento de F. A. Hayek. No trabalho é esclarecida a eventual conveniência de regimes autoritários no pensamento de Hayek. Após, há uma contextualização da experiência de Roberto Campos quanto à ditadura militar brasileira, acompanhada de uma exposição da evolução de seu pensamento e aproximação da abordagem hayekiana no que diz respeito ao autoritarismo e às falhas da democracia. Por fim, argumenta-se que isso pode ser interpretado como um caso de difusão internacional do pensamento econômico.
\end{abstract}

Palavras-chave: F. A. Hayek. Roberto Campos. Difusão internacional do pensamento econômico.

\begin{abstract}
The aim of the paper is to enhance the comprehension of Roberto Campos's thinking, particularly with regard to his defense of authoritarian regimes, especially the Brazilian military dictatorship. The hypothesis of the work is that the subtle change in Campos's argument in defense of Brazil's military coup of 1964 may be related to the know fact that Campos's got closer to the thinking of F. A. Hayek during 70's and 80's. Hayek's conception of authoritarian regimes is clarified in the paper, followed by a discussion by the Review of Political Economy on the subject. Afterwards, there is a contextualization of Roberto Campos' experience regarding the military dictatorship, accompanied by an exposition of the evolution of his thought and approach of the Hayekian approach with regard to authoritarianism and the failures of democracy, which can be interpreted as a case of international diffusion of economic thought.
\end{abstract}

Keywords: F. A. Hayek. Roberto Campos. International diffusion of economic thought.

JEL Classification: B25; B29; B31.

\footnotetext{
* Os autores agradecem a Felipe Almeida, Gustavo Pereira da Silva, Herton Castiglioni Lopes, Rogério Arthmar e aos participantes dos Seminários de Pós-Graduação em Economia da UFES e da UFSCar, eximindo-os, contudo, dos erros e omissões remanescentes.

Universidade Federal do Paraná, Departamento de Economia. Curitiba, Paraná, Brasil.
} 


\section{1 lntrodução}

O objetivo do artigo é contribuir com o estudo do pensamento de Roberto de Oliveira Campos (1917-2001), especialmente em sua justificativa do regime militar brasileiro (1964-1985). De modo mais específico, será argumentado que a aproximação de Campos com o pensamento de F. A. Hayek (1899-1992) pode ajudar a compreender como Campos foi alterando, ainda que de forma sutil, o modo como defendia a existência do governo autoritário no Brasil. A hipótese é que Campos, após aproximar-se de Hayek, passou a argumentar explicitamente que uma democracia ilimitada é problemática e que uma ditadura de direita seria mais compatível com uma transição a uma democracia, quando comparada a uma ditadura de esquerda. Tal mudança no pensamento de Campos pode ser compreendida a partir da perspectiva da difusão internacional do pensamento econômico.

Campos, que era profissional de carreira do Itamaraty desde a ditadura do Estado Novo (1937-1945), serviu a diferentes governos em diversas funções ao longo das décadas de 1950 e 1960. Ele foi, por exemplo, presidente do Banco Nacional de Desenvolvimento Econômico e Social (BNDES) sob a presidência de Juscelino Kubitschek e ministro do Planejamento e da Fazenda com Castello Branco. Intercalou esses períodos com momentos em que serviu no exterior, tais como quando participou da delegação brasileira em Bretton Woods e quando foi indicado por Vargas, nos anos 1950, para o consulado do Brasil em Los Angeles, e por João Goulart para a embaixada em Washington. Serviu também ao Itamaraty no exterior quando foi indicado por Geisel para ser embaixador em Londres, cargo que ocupou entre fevereiro de 1975 e agosto de 1982. Neste ano voltou ao Brasil para concorrer (e ser eleito) ao cargo de senador por seu estado natal, Mato Grosso.

Campos foi apresentado ao pensamento de Hayek por Eugênio Gudin. Na segunda metade da década de 1970, Gudin agendou uma visita a Campos enquanto este era embaixador em Londres. Aproveitando a oportunidade, Campos resolveu realizar um jantar e convidar Lionel Robbins e Hayek como uma homenagem, já que eram "[...] duas figuras do mundo econômico pelas quais [Gudin] nutria extremo respeito [...]" (CAMPOS, 1994a, p. 1021). ${ }^{1}$

Esse jantar aconteceu em maio de 1978, e nele Campos foi presenteado por Hayek com um exemplar do seu recém lançado livro New studies in philosophy, politics, economics and the history of ideas (CAMPOS, 1996c). ${ }^{2}$ No livro, Hayek (2008) trata sobre variados temas. Um deles é a deturpação e o mau uso da palavra de-

1 Também participaram deste jantar James Meade, Nicholas Kaldor e Hans Singer (CAMPOS, 1994a, p. 1021).

2 Esse exemplar se encontra autografado por Hayek na biblioteca particular de Roberto Campos, que hoje pertence à biblioteca da Universidade Positivo. A propósito, os autores do presente trabalho tiveram acesso à pasta destinada a documentos de Roberto Campos pertencente aos arquivos de Hayek que se encontram no Hoover Institution, na Califórnia (Estados Unidos). Porém, não foi encontrada informação que fosse pertinente à pesquisa aqui apresentada. 
mocracia, já que a democracia seria ligada à concepção do poder ilimitado do governo. Hayek (2008) recupera um conceito que ele já havia apresentado anteriormente, o de demarquia. Segundo o austríaco:

It is greatly to be regretted that the word democracy should have become indissolubly connected with the conception of the unlimited power of the majority on particular matters. But if this is so we need a new word to denote the ideal which democracy originally expressed, the ideal of a rule of the popular opinion on what is just, but not of a popular will concerning whatever concrete measures seem desirable to the coalition of organised interests governing at the moment. If democracy and limited government have become irreconcilable conceptions, we must find a new word for what once might have been called limited democracy. We want the opinion of the demos to be the ultimate authority, but not allow the naked power of the majority, its kratos, to do rule-less violence to individuals. [...] We might perhaps describe such a political order by linking demos with archein and call demarchy such a limited government in which the opinion but not the particular will of the people is the highest authority (HAYEK, 2008, p. 96-97).

Por ocasião da entrega do livro, Hayek chamou atenção, nas palavras de Campos, “[...] para o capítulo 5, que começa com uma confissão: há dez anos se preocupava ele, infrutiferamente, em entender o sentido da expressão 'justiça social'" (CAMPOS, 1996c, p. 190). Esse tema acabou sendo tratado por Campos em diversos trabalhos, nos quais concordava com Hayek que o termo deveria ser substituído por "normas justas de conduta" e que, portanto, “[...] as regras do jogo é que devem ser justas: o resultado será sempre diferente, dependendo das faculdades e do esforço de cada um [...]" (CAMPOS, 1996c, p. 191).

Nota-se que, a partir de 1978, diversos foram os tópicos em que Campos começou a citar Hayek, não se limitando somente sobre o uso incorreto da expressão "justiça social”, mas, por exemplo, em acreditar e citar a concepção hayekiana de que "[...] a economia é o resultado das ações dos homens e não de suas intenções [...]" (CAMPOS, 1988b, p. 114).

Como se sabe, Campos teve uma mudança ideológica durante sua vida, de uma vertente mais desenvolvimentista, que ainda prezava pela intervenção e planejamento governamental, para um adepto do liberalismo, identificando-se com o pensamento hayekiano. Segundo Bielschowsky (2000), tratando da década de 1950:

É necessário advertir que Campos estava, naquela época, longe de ser um economista "ortodoxo", ou seja, de pensar de acordo com os postulados liberais ou neoliberais; No início dos anos 50, sua defesa da industrialização com apoio do Estado e de planejamento colocava-o em franca confrontação teórica com a essência da ortodoxia liberal e o identificava com a nata da heterodoxia teórica do subdesenvolvimento, isto é, com autores como Prebisch, Nurkse, Singer, Lewis e outros [...] (BIELSCHOWSKY, 2000, p. 105). 
Adiante, Bielschowsky (2000) afirma que Campos, nos anos 1950, “[...] posicionava-se então contra as ideias que Hayek e Von Mises expuseram na famosa controvérsia dos anos 30 [...]" (BIELSCHOWSKY, 2000, p. 110). ${ }^{3}$

Não surpreende, portanto, que Campos tenha experimentado divergências intelectuais com Gudin - por quem, aliás, nutria grande apreço. Os desacordos com Gudin, contudo, "[...] diminuíram rapidamente, à medida que adquiri maturidade intelectual e experimentei desilusões quanto à eficácia do serviço público [...]" (CAMPOS, 1994a, p. 168). Campos chegou a se desculpar com Gudin, afirmando que "[...] depois de exposto por tempo muito mais longo à pregação de Von Mises e Hayek, reconheço que eram válidas as críticas que fazia Eugênio Gudin à minha ingenuidade de planejador [...]" (CAMPOS, 1994a, p. 616). ${ }^{4}$

Campos viria a qualificar Hayek e Mises como grandes profetas do colapso do socialismo (CAMPOS, 1991, p. 85), tendo chegado, inclusive, a escrever o prefácio da edição lançada em 1994, pela Biblioteca do Exército, de O caminho da servidão, em homenagem aos 50 anos da obra. Nele agradeceu à iniciativa da Biblioteca do Exército de "[...] facilitar o acesso do nosso público militar a essa obra indispensável para todos aqueles que querem pensar mais fundo sobre os problemas e a realidade de nosso tempo [...]" (CAMPOS, 1994b). Delfim Netto relata que Campos teria confessado a ele: "Delfim, perdi muito tempo com os economistas. Eu deveria ter aproveitado todo ele apenas estudando o Hayek!” (DELFIM NETTO, 2001).

O presente artigo expõe a hipótese de que é possível enxergar na forma como Campos passou a justificar a necessidade do regime autoritário no Brasil, uma faceta da sua transformação em liberal e da sua manifesta admiração por Hayek. Com isso, pretende-se colaborar com esforços de pesquisa que buscam contextualizar e compreender melhor o pensamento de Roberto Campos. Nesse sentido, o artigo se propõe a complementar trabalhos como os de Ganem (2000), Godoi (2009), Madi (2007), Perez (1999), e Schmitz e Bittencourt (2014). Busca-se suprir uma lacuna nessa relevante literatura a respeito do pensamento de Roberto Campos.

Para isso, o artigo se valerá de pesquisas recentes que buscam esclarecer a relação entre Hayek e o autoritarismo, e, de forma mais específica, realizar uma

3 Essa famosa controvérsia dos anos 1930 é o debate do cálculo econômico socialista (ver, a respeito, Barbieri (2013)). Sobre a "conversão" de Roberto Campos, ver Ganem (2000). Campos chegou a escrever que "Os regimes capitalistas já experimentaram sua quota de desencanto no tocante ao profético otimismo do liberalismo da escola manchesteriana. Nenhum mercado, por si só guiado pela mão invisível, levou a uma distribuição ideal da renda, nem o livre comércio levou a uma ótima distribuição entre as nações dos ganhos de renda e produtividade. O intervencionismo estatal, hoje generalizado e o protecionismo comercial, assim como várias modalidades do planejamento econômico, ora em voga, são um constante desmentido do profético otimismo do liberalismo econômico de antanho" (CAMPOS, 1964, p. 219).

4 "Cheguei mesmo - horresco referens - à tolice, que Gudin nunca me perdoou, de escrever o seguinte: 'As objeções de Hayek e Von Mises sobre a irracionalidade dos preços e de fatores nas economias planificadas teriam sido destruídas, em grande parte, pela análise de Barone, Taylor e Lange'" (CAMPOS, 1994a, p. 169). 
compreensão mais qualificada a respeito do suporte dado por Hayek à ditadura de Pinochet no Chile. Isso foi tema de debate recente na Review of Political Economy, no ano de 2014, através de artigos de Farrant e McPhail (2014), Nell (2014), Meadowcroft e Ruger (2014) e Burczak (2014). Além desses, outros textos também têm lidado com o tema, tais como os de Knutsen (2016), Nientiedt e Ekkehard (2015) e Caldwell e Montes (2015).

Este artigo contém, além desta introdução, mais quatro seções. Na seção 2, discute-se a questão da difusão internacional do pensamento econômico. Esta seção serve como uma espécie de fundamentação metodológica para o presente trabalho, na medida em que a perspectiva apresentada tem se mostrado útil na compreensão da História do Pensamento Econômico brasileiro, como se depreende de trabalhos recentes como os de Bruzzi Curi e Cunha (2015), Bruzzi Curi e Lima (2015), Cavalieri e Curado (2016) e Silva (2016). ${ }^{5}$

Na seção 3, apresentam-se os principais elementos do pensamento de Hayek sobre o funcionamento e as falhas da democracia, além da interpretação de Hayek para a situação chilena sob Pinochet.

Na seção 4, contextualiza-se a participação de Roberto Campos no regime militar que foi instaurado no Brasil em 1964. Aborda-se também o pensamento de Campos quanto à democracia e suas fragilidades. A seção traz também uma breve exposição de sua aproximação com as ideias de Hayek.

Por fim, a seção 5 traz as considerações finais.

\section{Difusão Internacional do Pensamento Econômico}

O estudo da difusão internacional do pensamento econômico pode contribuir para uma maior compreensão de como se formam as ideias no campo da ciência econômica e como são aplicadas em diferentes contextos. A presente seção tem o objetivo de discutir o assunto, de modo a subsidiar as considerações finais do artigo.

Para Lluch, o fenômeno da difusão internacional ocorre naturalmente a partir da experiência diária dos indivíduos, seja advinda da vida acadêmica, seja da vida profissional (CARDOSO, 2009). Os países apresentam diferentes níveis de desenvolvimento de ideias no campo da ciência econômica. Essas diferenças podem ser explicadas a partir de vários fatores, tais como o desenvolvimento nos meios de transmissão, a velocidade de circulação de livros estrangeiros, a facilidade de acesso a revistas acadêmicas de topo, o conhecimento geral de outras línguas, a quantidade e a qualidade das traduções no país receptor da informação e o grau de autonomia científica e reconhecimento acadêmico. Assim, surge um de-

5 Cardoso (2009) traz uma série de estudos que usam a perspectiva da difusão internacional do pensamento econômico para melhor compreensão de episódios da história do pensamento econômico. 
sequilíbrio entre os países que possuem uma longa tradição no desenvolvimento e criação da ciência econômica e os países que sofrem de algumas das restrições mencionadas, que, eventualmente, só podem adaptar o discurso científico das influências externas.

É importante ressaltar que nem sempre os países irão apenas aceitar essas influências. A aceitação estará atrelada às particularidades encontradas no país receptor, podendo ser econômicas, sociais, políticas ou do ambiente científico. As restrições a essa difusão do pensamento econômico vão se esvaecendo conforme ocorre a evolução desse processo de circulação do conhecimento. Ele é facilitado pelo avanço das revistas em papel e, principalmente, das revistas eletrônicas, que conseguem muitas vezes ultrapassar as barreiras geográficas, tornando muito mais rápida a transmissão do pensamento econômico.

Coats e Colander (1989) expõem que o processo de disseminação das ideias não é simplesmente a disseminação da "melhor ideia", já que, se fosse o caso, o seu estudo se tornaria algo fácil. Para eles, "[...] studying the spread of ideas is like studying subatomic particles with half-lives of nanoseconds [...]" (COATS; COLANDER, 1989, p. 1). Os autores apontam que a maioria dos economistas passa a se ver como cientistas e, com isso, tentam usufruir do maior número de informações possíveis, sem buscar uma determinada vertente de pensamento econômico para defender e pregar. Isso justifica o processo de disseminação não se resumir às "melhores ideias", mas ser um processo difícil a ser estudado. Os autores falam de três modelos para se compreender a disseminação das ideias: a) o modelo de contágio; b) o mercado das ideias; e c) a teoria da informação.

O modelo do contágio busca comparar as ideias no campo da ciência econômica com doenças contagiosas. Assim, as ideias se espalhariam pela população da mesma maneira que as doenças contagiosas o fazem: "[...] we might expect an idea to gather momentum, spread rapidly, and eventually decline as a larger and larger proportion of the susceptible population is contacted [...]" (COATS; COLANDER, 1989, p. 11).

Por sua vez, o modelo do mercado de ideias busca compará-las com um mercado no qual essas ideias possuiriam oferta e demanda. Tal oferta de ideias seria apresentada pelos economistas em geral, e os demandantes dessas ideias seriam os políticos (que precisariam delas para suas políticas econômicas), empresários (que visariam previsões, minimização de custos, fixação de preços e outras ideias benéficas para o uso empresarial) e estudantes e leigos, que buscariam conhecimento sobre os temas econômicos.

Para os autores, tal processo não pode ser comparado a uma concorrência perfeita, mas sim a uma situação em que exista poder desigual entre os ofertantes de ideias. Isso ocorre em função das preferências dos demandantes de ideias, que acreditam que a reputação e a posição dos ofertantes são características funda- 
mentais na hora da escolha. Assim, tal modelo possui um caráter complexo, já que é difícil mensurar as restrições e benefícios que são criados nesse contexto da concorrência dinâmica.

O último modelo, o da teoria da informação, é baseado em fontes e receptores de informação interligados por canais de transmissão. As informações seriam as ideias econômicas transmitidas. Os agentes seriam os economistas. Os receptores seriam os políticos, empresários, público leigo e os estudantes, enquanto os canais de transmissão seriam materializados por indivíduos, grupos e instituições. Assim, o papel do economista seria o de pensar ideias úteis para a sociedade em geral e codificá-las para que possam ser mais bem transmitidas através das instituições. Estas possuem o papel de transmitir as ideias e decodificá-las para que os formuladores de políticas possam usá-las.

\section{Hayek, os Limites da Democracia e o Caso do Chile}

No contexto de sua batalha de décadas contra o socialismo e o keynesianismo, Hayek deixou transparecer uma preocupação com os problemas que poderiam emergir da democracia associada à arbitrariedade da atuação do Estado. A solução para tal arbitrariedade seria a restrição do poder estatal a partir do seguimento da rule of law.

Em The road to serfdom, publicado pela primeira vez no ano de 1944, Hayek (2010) aponta que o problema reside no planejamento, sendo que este se mostra inconsistente com a democracia, levando a população a se tornar descrente com a mesma e conceder maiores poderes para um indivíduo, de modo a contornar tal situação.

Já em The constitution of liberty, publicado originalmente em 1960, Hayek (1983) ressalta que um governo exercido por uma elite culta pode ser, muitas vezes, mais eficaz do que um governo democrático, fato que, segundo Hayek, não justifica que a democracia caia em desuso, já que esta faz com que a população busque maior entendimento sobre os assuntos públicos.

Por sua vez, no volume 3 de Law, legislation and liberty, publicado originalmente no ano de 1979, Hayek (1985b) demonstra estar muito infeliz com o rumo que a democracia tomou e com o que ela produzirá no futuro. Ele deixa de enfatizar a crença de que a democracia não consegue exercer o planejamento desejado pela economia planificada para expor sua ideia de que as ações realizadas pelo governo não são as que seriam democraticamente aceitas, cedendo espaço à atuação dos grupos de pressão.

A evolução do pensamento de Hayek a esse respeito foi explicada por Miller da seguinte maneira:

Hayek is much more favourable to democracy in The Constitution of Liberty than in Law, Legislation and Liberty. In the former, he attributes democracy's excesses mostly to a lack of understanding, the solution to 
which is education or enlightenment. Later Hayek came to believe that democracy had evolved into unlimited or arbitrary government and had become something of a game in which government tries to maintain a majority coalition by satisfying the demands of a multitude of special interests (MILLER, 2010, p. 96).

\subsection{Hayek e o Chile}

Pinochet havia alcançado o poder, como presidente da junta militar, após o golpe que derrubou o presidente Allende em 11 de setembro de 1973. Como explicam Caldwell e Montes (2015), o final do governo Allende havia sido marcado pela desorganização econômica, inflação alta, greves e elevada tensão política e social. Os primeiros meses do novo governo militar se caracterizaram pela sistemática e forte perseguição aos opositores do novo regime, com frequentes casos de tortura e execução. Esse tipo de ação persistiu durante toda a ditadura militar chilena, mas a intensidade com que ocorreu nos primeiros meses do novo governo fez com que houvesse repercussão na comunidade internacional, tendo o país recebido duas visitas de representantes do grupo de direitos humanos da Organização das nações Unidas (ONU). Esse grupo produziu dois relatórios que condenavam a ação do governo chileno, em 1975 e 1976.

Ainda de acordo com Caldwell e Montes (2015), Pinochet, presidente da junta militar e da República (este último cargo a partir de 1974), sob influência dos Chicago boys, implantou, nos primeiros anos do novo regime, reformas econômicas que envolviam a privatização de empresas públicas (inclusive bancos), demissão de funcionários públicos, abertura econômica, ajuste fiscal e desvalorização cambial. Houve a queda da inflação, mas o desemprego elevou-se, ficando acima do patamar de $18 \%$ entre 1975 e 1977.

No entanto, após o choque inicial, a economia começou a dar sinais de recuperação, de modo que Caldwell e Montes (2015) descrevem a situação econômica chilena durante as visitas de Hayek (em 1977 e 1981) da seguinte maneira: "Hayek's visits [...] took place while the Chilean economy was on the rebound: between 1975 and 1981 the average annual growth rate was 7.3 \%. [...] Hayek's second visit, in April 1981, took place during a booming and optimistic economic time." (CALDWELL; MONTES, 2015, p. 273 ).

A promulgação de uma nova constituição em 1980, explicam Caldwell e Montes (2015), com um dispositivo que previa a realização de um plebiscito em 1988 sobre a continuidade de Pinochet na presidência da República, trouxe a perspectiva de que um retorno à democracia estava a caminho.

Em 1974, Hayek ganhou o prêmio Nobel de Economia. Isso fez com surgisse uma série de convites para palestras e participações em debates pelo mundo. Em 
tal contexto, a primeira visita de Hayek ao Chile ocorreu em novembro de 1977, oportunidade em que Hayek e Pinochet tiveram um encontro. ${ }^{6}$

De acordo com Caldwell e Montes (2015), Hayek declarou ao jornal El Mercurio que a conversa com Pinochet se centrou no tema da ineficácia da democracia ilimitada, nome usado por Hayek para a democracia sem normas para restringir a ação governamental. Caldwell e Montes contam que, segundo Hayek, Pinochet ouviu atentamente o que ele tinha para dizer requisitando, inclusive, documentos sobre o que Hayek havia escrito sobre esse tema. Também a El Mercurio, Hayek fez questão de mencionar que se surpreendeu com o Chile, já que acreditava que iria encontrar um país menos desenvolvido. Ele ainda buscou acalmar os chilenos, esclarecendo que as reformas econômicas que estavam sendo praticadas poderiam parecer um tanto quanto severas, mas eram necessárias e que a economia chilena estava caminhando na direção correta (CALDWELL; MONTES, 2015).

Muitas críticas vieram a partir da visita ao Chile e das declarações posteriores de Hayek, nas quais ele tentou defender que em algumas situações um regime ditatorial pode defender a liberdade individual de forma mais eficaz que uma democracia ilimitada. Uma dessas declarações foi em carta publicada no jornal The Times de Londres no dia 3 de agosto de 1978 (HAYEK, 1978b). Nela, Hayek afirmou que " $[. .$.$] except in the direct democracy based on an assembly of all citizens,$ a democracy can never create itself but must Always be the product of the authoritarian decision of a few [...]" (HAYEK, 1978b, p. 15).

Na mesma carta, Hayek declarou: "I have not been able to find a single person even in much maligned Chile who did not agree that personal freedom was much greater under Pinochet than it had been under Allende [...]" (HAYEK, 1978b, p. 15). Ainda nessa carta, Hayek enfatizou que o ideal seria uma democracia limitada. Em suas palavras:

That a limited democracy is probably the best possible known form of government does not mean that we can have it everywhere, or even that it is itself a supreme value rather than the best means to secure peace, a defensor pacis or instrument of peaceful change of government (HAYEK, 1978b, p. 15).

Na segunda viagem que fez ao Chile, Hayek concedeu duas entrevistas para o jornal El Mercurio. Na primeira, publicada no dia 12 de abril de 1981, conforme tradução de trechos trazidos por Caldwell e Montes (2015), quando perguntado sobre o que pensava sobre ditaduras, Hayek respondeu que era completamente contra, mas que elas podem ser necessárias durante um período de transição, enfatizando que ele, pessoalmente, preferia uma ditadura liberal ao invés de um

6 Para informações sobre o contexto chileno antes e durante a ditadura de Pinochet, bem como sobre as visitas de Hayek ao Chile, ver Caldwell e Montes (2015). As informações ora mencionadas a respeito dessas viagens estão baseadas nesse artigo. 
governo democrático que não assegurasse as liberdades individuais de seu povo. Na visão de Hayek, a ditadura no Chile estava para se tornar uma democracia com princípios liberais, então essa ditadura transicional teria benefícios no longo prazo. Essa ditadura transicional seria necessária, segundo Hayek, quando "[...] a government is broken, and there are no recognized rules [...]" (HAYEK apud CALDWELL; MONTES, 2015, p. 299). Portanto, a democracia ilimitada traria resultados tão ruins que seria necessário um período de transição com uma ditadura para que a sociedade tivesse assegurada sua liberdade individual e, assim, pudesse voltar para um sistema democrático com regras e restrições ao poder governamental.

Ainda segundo o relato de Caldwell e Montes (2015), na segunda entrevista, publicada uma semana depois, em 19 de abril de 1981, Hayek expôs suas convicções acerca da necessidade de restrições ao aparelho governamental e quais seriam as consequências de não existirem tais restrições. Hayek disse acreditar que a ditadura teria o poder de se limitar e guiar o país para o liberalismo, enquanto uma democracia sem restrições pode não conseguir isso. Hayek afirma estar consciente de que isso pode não acontecer, porém, em certas situações, a saída autoritária pode ser a única esperança. Para Caldwell e Montes (2015), essa é a definição mais precisa do que Hayek acreditava, ou seja, a ditadura para Hayek não era desejável, mas em algumas ocasiões somente ela faria com que fosse possivel recuperar a liberdade individual. ${ }^{7}$

Segundo Farrant e McPhail (2014), Hayek já havia desenvolvido sua concepção de ditadura transicional anos antes de Pinochet surgir como presidente do Chile, de modo que o suporte ao governo de Pinochet não teria sido algo súbito. Para os autores, a referida transição poderia ser considerada uma alquimia que estabeleceria uma maior garantia dos direitos individuais em determinada sociedade. Tal alquimia seria necessária em alguns casos de democracia ilimitada.

Farrant e McPhail (2014) produziram um esquema (Figura 1) para representar o rumo que pode ser tomado pela democracia na visão de Hayek. Hayek faria a distinção entre dois tipos de democracia ilimitada: de um lado, aquelas que seriam "aproveitáveis" e poderiam, como Hayek desejava, fazer "[...] alterações da estrutura constitucional necessárias à preservação da liberdade [...]” (HAYEK, 1985b, p. 137) e, de outro, aquelas que já teriam atingido um ponto crítico e não poderiam fazer tais alterações. Assim, o primeiro tipo de democracia ilimitada teria alguma

$7 \quad$ Hayek era um forte crítico do socialismo, e na época, não só no Chile, mas em muitos outros países, governos considerados socialistas eram tirados do poder a partir de ditaduras, tornando, de certa forma, as ditaduras como uma "solução" para o combate ao socialismo. Chama a atenção o fato de Hayek não se opor às violações dos direitos humanos no Chile. Para Caldwell e Montes (2015), pode ser imaginado que ele não soubesse muito sobre o Chile antes da primeira visita. Nessa oportunidade, ele se surpreendeu com o desenvolvimento do país, impressão que foi confirmado na sua segunda visita em 1981, quando o país vivia três anos de forte crescimento econômico. Assim, os autores acham possível que Hayek tenha desacreditado na veracidade das notícias sobre as violações dos direitos humanos quando viu as condições do país, ainda mais quando a maioria das pessoas que conheceu na sua primeira viagem eram membros da elite chilena que estavam apoiando o regime militar. 
chance de "corrigir seus princípios"8 e, assim, chegar a uma democracia limitada que preservaria a liberdade individual.

Tais cenários podem ser representadas nos pontos A e B da Figura 1. Ao chegar no ponto $\mathrm{C}$ da Figura 1, é possível perceber que não há mais a opção de fazer alterações para a preservação da liberdade. Chegou-se ao ponto crítico, onde a democracia ilimitada se tornará um totalitarismo ou será necessária uma ditadura de transição para que seja recuperada a liberdade individual. Cabe ressaltar que a partir do emprego da ditadura (ponto D), existirão duas alternativas: ou a ditadura efetivamente será uma ditadura de transição e imporá regras (fazendo com que uma democracia limitada que preserva a liberdade individual se faça possível), ou se tornará um despotismo militar.

Figura 1 - A escolha entre a democracia ilimitada a ditadura de transição

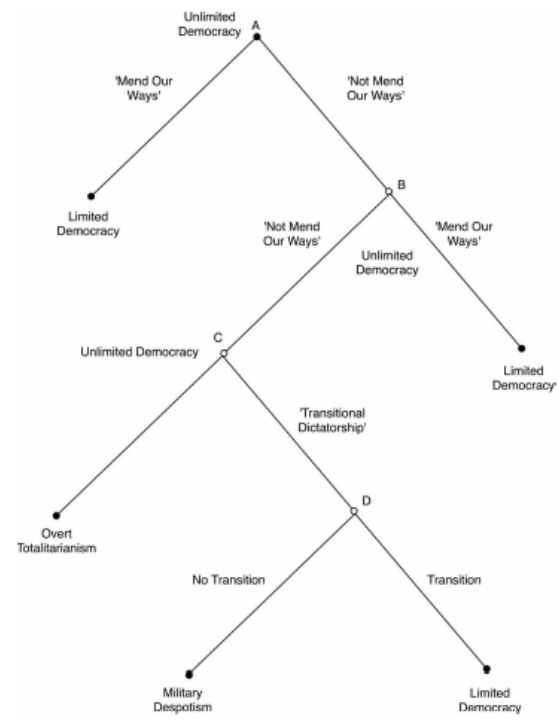

Fonte: Farrant e McPhail (2014).

Farrant e McPhail (2014), produziram um quadro (Figura 2) para exemplificar a tomada de decisão de Hayek entre o governo de Allende e a ditadura de Pinochet.

8 "O que pretendi afirmar em O caminho da servidão certamente não foi que todo afastamento, mesmo pequeno, daquilo que considero os princípios de uma sociedade livre nos arrastará inevitavelmente para um sistema totalitário. Minha intenção foi fazer a advertência que, numa linguagem mais familiar, se expressa na frase: 'Se não corrigir seus princípios, você vai se dar mal'" (HAYEK, 1985a, p. 65). 
Figura 2 - A escolha entre o governo "totalitário" de Allende e o governo "autoritário" de Pinochet

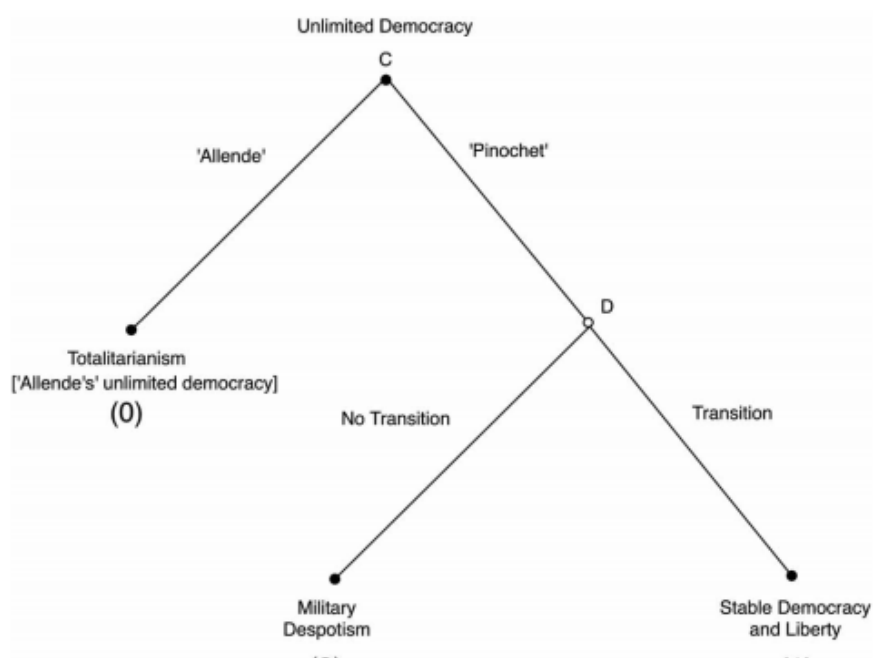

(0)

(1)

Fonte: Farrant e McPhail (2014).

A decisão se dá entre a certeza do totalitarismo (a democracia ilimitada de Allende) e o governo autoritário (Pinochet) que pode levar tanto para um despotismo militar, quanto para uma democracia limitada que assegure a liberdade individual. Sabendo-se que o resultado desejado por Hayek era uma democracia limitada que pudesse garantir a liberdade individual, e, assim, atribuindo valores de zero (fracasso da garantia de liberdade individual) para o governo totalitário de Allende e para a opção de despotismo militar de Pinochet e de um (sucesso da garantia de liberdade individual) para o governo com democracia limitada, é fácil identificar qual seria a tomada de decisão de Hayek: o resultado que o governo de Pinochet pode alcançar será de zero ou um, enquanto Allende só poderá alcançar zero. Assim, na pior das hipóteses, o governo de Pinochet apresentará o mesmo resultado (indesejado) que o de Allende. Porém com Pinochet haveria ao menos a esperança de que o melhor resultado pudesse ser alcançado.

\section{Roberto Campos}

Explicada a defesa que Hayek fazia da utilidade eventual de governos totalitários, em particular no caso de Pinochet no Chile, passa-se a tratar do pensa- 
mento de Campos com relação à conveniência da ditadura militar brasileira. $\mathrm{O}$ propósito é mostrar que Campos constrói um argumento muito próximo ao de Hayek conforme conhece a obra do austríaco. Isso aparece de forma mais clara no período em que Campos foi embaixador em Londres - precisamente a época em que as cartas de Hayek expressando sua visão a respeito da situação chilena foram publicadas no Times.

Pode-se argumentar que a mudança no pensamento de Campos não ocorreu somente quanto à necessidade de planejamento econômico, conforme apontado na introdução deste artigo. Seu ponto de vista quanto ao autoritarismo, objeto de estudo do presente trabalho, foi amadurecendo, ainda que de modo sutil, com o passar do tempo.

A "Revolução de 64" (expressão preferida por Campos) e o subsequente regime militar no Brasil tiveram impacto relevante sobre a trajetória de Campos. Cabe ser destacado que Campos não acreditava, na época, que ocorreria uma intervenção militar, já que as Forças Armadas possuíam uma mentalidade extremamente legalista e, assim, só interviriam "[...] em caso de comoção social ou ameaças à disciplina militar [...]" (CAMPOS, 1996b, p. 543). Entretanto, "[...] no curto espaço de dezoito dias sucederam-se três provocações de tintura esquerdista: o comício de 13 de março, a rebelião dos marinheiros no dia 27 e a festa dos sargentos no dia 31 [...]" (CAMPOS, 1996b, p. 549). Diante disso, Campos afirma:

A presença militar na vida política brasileira e a implantação de um Executivo forte responderam a uma exigência de um determinado momento histórico. A democracia brasileira, em 1964, teria de outra forma perecido em mãos de um autoritarismo de esquerda, após um interregno anárquico. E havia necessidade de restauração da disciplina social. Mas acredito também que essa presença deve ser temporária, buscando-se restaurar gradualmente a legitimidade e a representatividade características dos sistemas políticos viáveis. Pois sendo este essencialmente um fenômeno de longo prazo, teríamos de considerar o regime de exceção numa dieta permanente, e não uma correção transicional (CAMPOS, 1987a, p. 211).

No ano de 1964, Campos estava planejando seguir carreira no setor privado, quando foi pego de surpresa pelo convite de Castello Branco para ser Ministro do Planejamento de seu governo. Campos argumentou com o presidente Castello Branco que tal tarefa não seria fácil, já que seria necessária uma "[...] dolorosa preparação de terreno [...]" (CAMPOS, 1996b, p. 560) com resultados lentos, antes de se planejar um crescimento, recebendo de Castello Branco a resposta de que ele não estava preocupado com questões eleitoreiras, mas sim de salvar o país do caos. Após o aceite de Campos, foi iniciado o Programa de Ação Econômica do Governo (Paeg), um vasto programa de reformas modernizantes, com o objetivo 
de "[...] debelar a inflação e preparar o país para o capitalismo competitivo [...]" (CAMPOS, 1991, p. 86). ${ }^{9}$

Em 1967, Campos creditou a intervenção militar nas nações recentemente descolonizadas ao problema da modernização e à construção da nacionalidade, em que as Forças Armadas, “[...] mais bem equipadas que os primitivos agrupamentos políticos [...]" (CAMPOS, 1969a, p. 17), deveriam intervir de forma a suprir tal necessidade. Campos via a inflação, um problema presente no Brasil durante o período, como uma outra justificativa para a intervenção militar, já que a sua contenção teria de vir por políticas que não provocariam entusiasmo eleitoral, necessitando, assim, de um sistema de decisão que não se sentisse obrigado a agradar o eleitorado.

Outro fator usado por Campos (1967a) como justificativa para tal intervenção foi justamente o comportamento dos políticos de agradar o eleitorado. Sem a intervenção militar, dizia, os políticos não teriam " [...] abandonado o distributivismo paternalista e a barganha pessoal [...]" (CAMPOS, 1967a, p. 83).

$\mathrm{Na}$ época, era bem difundida a ideia de que a necessidade da ditadura militar no Brasil era transitória. Campos concordava com tal transitoriedade do regime militar. Em 1970, demonstrou acreditar que o regime era necessário para a restauração da disciplina social, argumento que já havia sido usado em $1967,{ }^{10}$ para se “[...] restaurar gradualmente a legitimidade e a representatividade características dos sistemas políticos viáveis [...]" (CAMPOS, 1987a, p. 211). ${ }^{11}$

Para Campos, o regime instalado no Brasil em 1964 surgiu em um momento em que se fazia necessária uma “[...] restauração da disciplina social, após impasses políticos, que levariam a sociedade ao imobilismo institucional ou ao radicalismo subversivo [...]" (CAMPOS, 1969a, p. 18). Assim, a necessidade da intervenção militar foi "[...] resultado do fracasso do instrumental democrático, e não uma causa da 'crise política' [...]" (CAMPOS, 1969a, p. 18-19).

Segundo Campos (1996b), "[...] não existia em 1964 uma idílica opção entre diferentes estilos de democracia, como presumem muitos de nossos politólogos. A opção real era entre dois tipos de autoritarismo: o autoritarismo-totalitário e o autoritarismo-liberal [...]” (CAMPOS, 1996b, p. 95). ${ }^{12}$ Campos considerava que era

9 Santos (2000) estuda a atuação de Campos como Ministro do Planejamento de Castello Branco, em particular no que diz respeito à elaboração e execução do PAEG.

10 "A explicação residirá talvez numa terceira função que as Forças Armadas, graças a seu maior grau de coesão institucional e organizacional, são chamadas ocasionalmente a exercer: a restauração da disciplina social, após impasses políticos, que levariam a sociedade ao imobilismo institucional ou ao radicalismo subversivo" (CAMPOS, 1969a, p. 18).

11 "A democracia brasileira, em 1964, teria de outra forma perecido em mãos de um autoritarismo de esquerda, após um interregno anárquico. E havia a necessidade da restauração social. Mas acredito também que essa presença deve ser temporária, buscando-se restaurar gradualmente a legitimidade e a representatividade características dos sistemas políticos viáveis" (CAMPOS, 1987a, p. 211).

12 Campos (1974) atribui tal distinção a André Philip sem, contudo, indicar a fonte utilizada. Essa distinção feita por Campos entre autoritarismo-totalitário e autoritarismo-liberal será retomada 
questão de tempo o processo democrático ser violado. Ele relata ter respondido da seguinte maneira a Robert Kennedy, durante sua visita ao Brasil em 1965, quando o então senador por Nova Iorque criticou e lamentou que a democracia tivesse sido interrompida pelo movimento militar:

Não se tratava de saber se o processo democrático e constitucional seria violado, mas quando, como e por quem... Goulart, a meu ver, não tinha a mínima intenção de presidir a uma transmissão democrática normal. Não pretendia entregar o poder a Lacerda e tinha se recusado a construir qualquer outra alternativa eleitoral. Contava com a implantação de uma república sindicalista, uma espécie de "estado novo" com sinais trocados. Talvez pretendesse ser o Leon Blum de uma nova frente popular, mas provavelmente seria antes seu Kerensky [...] (CAMPOS, 1994a, p. 761).

Goulart, na leitura de Campos, estaria presidindo a uma radicalização rumo a uma república sindicalista. Suas atitudes apontariam para uma tentativa de se manter no poder:

A partir da mudança de gabinete de junho de 1963, percebi que Goulart embarcaria numa orgia inflacionária, que procuraria justificar alegando a obsolescência das estruturas, somente retificável por reformas violentas, com a tonalidade esquerdista. Sua recusa tanto em apoiar Kubitschek, já candidato à reeleição, como em construir um candidato trabalhista, transmitiu-me a certeza de que não cogitava de um desfecho eleitoral normal (CAMPOS, 1994a, p. 537).

Instaurado o governo militar, Campos atribuía a Castello Branco a visão de que o novo regime implantado em 1964 deveria ser um "autoritarismo de transição" (CAMPOS, 1994a, p. 567), já que Castello desejava que a intervenção militar fosse "missionária e cirúrgica" (CAMPOS, 1985b, p. 24). Ademais, Castello buscava manter o Congresso e o Judiciário, pois acreditava que isso facilitaria uma futura “restauração democrática” (CAMPOS, 1994a, p. 567).

Em sua autobiografia publicada em 1994, Campos afirma que sua interpretação do momento vivido pelo Brasil em 1964, bem como do papel do regime instaurado naquele ano, era próxima à de Castello Branco:

Sem explicitar minha análise, senti que minha interpretação da crise brasileira se assemelhava à de Castello. O imediato deflagrador da crise política fora o populismo estatizante e esquerdista de Goulart. A Revolução de Março era o resultado e não a causa do impasse institucional, a que Goulart pretendia escapar pela implantação de uma república autoritária sindicalista. A intervenção militar fora algo relutante, tendo em vista a tradição legalista das Forças Armadas, a que Castello imaginava dar continuidade. Por isso ele favorecia uma autolimitação dos poderes e da

adiante. 
duração do processo revolucionário, assim como a preservação substancial da instrumentação política e judiciária (CAMPOS, 1994a, p. 567).

Entretanto, entre os militares havia duas tendências: a primeira, da qual Castello fazia parte, considerava a intervenção militar como uma função temporária, enquanto a segunda acreditava na existência de uma função mais duradoura:

Diferindo quanto à urgência e oportunidade de institucionalização democrática, pode-se detectar entre os militares duas tendências: a daqueles que consideram a intervenção militar na política uma missão temporária e a daqueles que a consideram uma função mais duradoura. Para aqueles, a intervenção militar na política deveria ser precisa nos objetivos e limitada no tempo. Seus objetivos deveriam ser: corrigir a indisciplina social, estancar a inflação, minorar os desequilíbrios sociais, lançar as bases para a retomada do desenvolvimento e compatibilizar as instituições democráticas com o reforço de segurança imposto pela contestação ideológica e pela guerrilha subversiva (CAMPOS, 1974, p. 229).

A posse de Costa e Silva como sucessor de Castello Branco representaria a vitória do segundo grupo e o consequente afastamento de Campos do regime militar.

Campos, então, parece ter acreditado desde o início do regime militar que a função das forças armadas era temporária e que se mostrava como a melhor alternativa diante da possibilidade de um governo autoritário de esquerda, ou mesmo da anarquia a que o país parecia, em sua visão, estar caminhando.

A aludida mudança, ainda que sutil, na argumentação exposta por Campos, assim não se relaciona especificamente com a pretensa rapidez da transitoriedade que seria adequada ao governo militar no Brasil - tal já era a visão do grupo castelista em 1964, do qual Campos fazia parte. A novidade jaz na comparação subjacente entre as capacidades que diferentes regimes autoritários teriam de promover a transição rumo à democracia, bem como a necessidade de que tal democracia fosse limitada.

De fato, Campos apresentou, em diferentes momentos, ressalvas quanto à crença excessiva na democracia. Ainda em meados da década de 1960, ele escreveu que "[...] se enxergamos na democracia algo mais que uma retórica de comício, é preciso saber se existe ou não um sistema de defesa que impeça sua destruição por processos subversivos, apoiados em ideologia totalitária [...]" (CAMPOS, 1967b, p. 272).

Já em capítulo de livro publicado em 1974, Campos, ao falar do "[...] quase inevitável recurso a métodos autoritários para conter os ímpetos distributivistas e paternalistas, na fase de capitalização acelerada dos países subdesenvolvidos [...]", propôs a "[...] distinção entre os regimes "autoritários-liberais [...]", que optam por planejamento descentralizado (como seria o caso do Brasil e do México) e os regimes "[...] autoritários-totalitários, que perfilham técnicas de planejamento centralizado segundo o estilo marxista [...]" (CAMPOS, 1974, p. 225). 
Ele retomaria tal distinção em 1977, pouco antes de seu encontro com Hayek e das cartas deste publicadas no Times. Nesse texto, ele reafirma a necessidade de se diferenciar os regimes autoritários entre "autoritários liberais" e "autoritários totalitários", nos quais os primeiros buscam a democracia como objetivo e "[...] mantêm, pelo menos num sentido formal, instituições democráticas. Admitem o pluralismo econômico e, em vários graus, preservam a liberdade individual [...]" (CAMPOS, 1985a, p. 48).

Campos, conquanto, de modo semelhante a Hayek, propunha a distinção entre dois tipos de autoritarismo, mas ainda não os qualifica da mesma maneira que o austríaco. Veremos que essa aproximação ficará mais explícita em escritos mais tardios do brasileiro.

$\mathrm{O}$ argumento que se procura levantar no presente artigo é que a aproximação com Hayek a partir de 1978 (ano do jantar na embaixada brasileira em Londres e da publicação das cartas de Hayek no Times) pode ajudar a compreensão de uma sutil mudança na argumentação de Campos. Ele passa, então, a defender que uma ditadura de direita, como a implantada no Brasil, seria, se comparada a uma ditadura de esquerda, de mais fácil remoção e transição rumo a uma democracia limitada. Uma situação crítica como a do Brasil no começo da década de 1960 (possivelmente equivalente ao ponto $\mathrm{C}$ da Figura 1) colocaria essa encruzilhada de modo que o autoritarismo de direita seria a escolha preferível.

Os regimes autoritários liberais seriam compatíveis com a busca da restauração da democracia, preservando instituições e não impondo uma submissão ideológica, enquanto os regimes autoritários totalitários não possuem as mesmas características:

Os regimes autoritários-liberais, por sua vez, proclamam a democracia como objetivo reconhecido e aceito; não impõem a submissão ideológica; e mantêm, pelo menos num sentido formal, instituições democráticas. Admitem pluralismo econômico e, em vários graus, preservam a liberdade individual (CAMPOS, 1985a, p. 48). ${ }^{13}$

Ademais, Campos (1988b) notava que os regimes socialistas apresentavam uma dificuldade relevante quando colocados diante da necessidade de transição para a democracia. Escrevendo a respeito do caso de El Salvador, Campos (1988a) argumenta: "[...] as esquerdas não querem partilhar o poder e sim capturá-lo. Se triunfantes, só admitiriam pluralismo partidário no sentido do bolchevique Bukharin - 'um partido no poder e os outros na cadeia' [...]" (CAMPOS, 1988a, p. 41). Já com relação à Nicarágua, defende que "[...] a ideologia socialista está resvalando para o tradicional impasse: - se restauradas as eleições, arruinar-se-ia a disciplina, socializante, e se canceladas estas, configurar-se-á o autoritarismo ideológico do sistema [...]" (CAMPOS, 1988a, p. 41).

13 Nota-se que essa passagem se refere ao texto relativo a uma conferência de 1977. O texto só foi publicado em 1985. Não se tem informações sobre possíveis alterações no conteúdo nesse intervalo de oito anos. 
Campos acreditava, com base na experiência dos tigres asiáticos, que, conforme houvesse um avanço no desenvolvimento econômico, haveria uma demanda pela democracia, já que "[...] o progresso econômico exige expansão da educação, e a educação gera demandas de liberdade [...]” (CAMPOS, 1996a, p. 92).

O ano de 1978, que se apresenta como chave no presente trabalho, foi marcado por alguns acontecimentos relevantes para a pesquisa. O primeiro deles foi o jantar oferecido por Campos a Gudin, em maio, que contou com a presença de Hayek. Isso foi seguido pelas cartas publicadas (julho e agosto) no Times, de Londres, nas quais Hayek contestava a democracia ilimitada, conforme exposto na seção anterior (HAYEK, 1978a, 1978b).

Já em 1979, Campos passou a argumentar que o autoritarismo não era “[...] um estúpido acidente de regressão da plenitude democrática para o Estado pretoriano [...]" (CAMPOS, 1987b, p. 310), já que o caos econômico e o impasse político já haviam chegado a tais níveis em alguns países que a opção não era mais entre a democracia e o autoritarismo, mas sim entre um autoritarismo de esquerda e um autoritarismo de direita, ressaltando que o autoritarismo de esquerda tende a não ser "biodegradável": "[...] na linguagem ambientalista de hoje, pode-se dizer que as ditaduras marxistas não são biodegradáveis, enquanto que o autoritarismo não-marxista o é [...]" (CAMPOS, 1987b, p. 310). Esse argumento foi reafirmado em entrevista para o programa Roda Viva, da TV Cultura, em 1997. ${ }^{14}$

Esse argumento parece coincidir com o de Hayek, sintetizado pelas figuras de Farrant e McPhail (2014) apresentadas anteriormente, de que a democracia ilimitada tende a chegar a uma situação em que um regime autoritário pode se tornar a única esperança para a liberdade individual no futuro.

Com o passar dos anos, os argumentos de Campos a favor da união de democracia e economia de mercado cresceram, julgando tal "capitalismo democrático" como o formato político ideal, que "[...] mais probabilidade tem de nos fornecer a delicada e desejada mistura de satisfação social, eficiência econômica e política. Em suma, o desenvolvimento com liberdade [...]" (CAMPOS, 1990a, p. 56).

Campos criticou severamente a Constituição de 1988, alegando que a mesma possuía mais "democratices" que democracia, já que buscava garantir direitos políticos, e não os direitos individuais. Campos participou ativamente da Assembleia Constituinte e tentou expor suas idéias, que, segundo Perez (1999), eram inspiradas em Hayek, já que, em suas palavras, seguiam a linha de que "[...] uma 'cultura' pré-existente deve produzir a lei; e esta, antes de se traduzir em 'direito', deve estar plenamente incrustada nos 'costumes' [...]” (PEREZ, 1999, p. 211).

Em discurso proferido por Campos na $132^{a}$ Sessão Extraordinária da Assembleia Nacional Constituinte, em 11 de agosto de 1987, afirmou:

14 Disponível em https://youtu.be/8247O1l6QPE?t=1h3m (acesso em 10/03/2018). 
Sou a favor das constituições-moldura e não das constituições-regulamento. O texto constitucional deve ser feito basicamente para proteger o indivíduo contra o arbítrio do Estado, estabelecer adequado balanço entre os poderes, delinear princípios econômicos, sociais e culturais para o livre exercício da criatividade individual, encontrando a liberdade de cada um, seu único limite no respeito à liberdade de terceiros. Isso, e nada mais. A Constituição não deve ser uma lei ou sequer um conjunto de leis. É um conjunto de normas de organização da sociedade, a partir das quais se fazem as leis (BRASIL, 1987, p. 458).

Para Perez (1999), o que Campos tentava transmitir aos demais constituintes era que "A democracia deve ter limites" (PEREZ, 1999, p. 211), fato que vai ao encontro do pensamento de Hayek, destacando a proximidade de seus argumentos.

\section{Considerações Finais}

Campos teve contato pessoal com Hayek no jantar em 1978, o que pode ser tido como um momento representativo de sua aproximação com o pensamento do austríaco. Não coincidentemente, tal evento aconteceu em Londres, no ano anterior à ascensão de Margaret Thatcher, conhecida admiradora da obra de Hayek e então a líder da oposição, ao cargo de primeira-ministra, e exatamente no ano da publicação das cartas de Hayek no Times, facilitando o acesso de Campos aos argumentos hayekianos aqui expostos.

Em tal contexto, é razoável a suposição de que houve a influência de Hayek para a mudança, ainda que sutil, da argumentação de Campos quanto às necessidades e funções do autoritarismo, conforme referido anteriormente. De fato, Perez (1999) atribui que as mudanças mais amplas de pensamento ocorreram no período em que Campos morou na Inglaterra, enquanto era embaixador em Londres, ou seja, no período de 1975 a 1982, e Ganem (2000) associa tal transição às décadas de 1970 e $80 .{ }^{15}$

Campos foi crítico da redemocratização do Brasil. Ele a qualificou como "um caso de democracia desperdiçada" (CAMPOS, 1996a, p. 92). Isso porque, em seu parecer, o regime implantado em 1964 não havia tido seu objetivo realizado, na medida em que buscava "[...] conter a onda socializante do anarco-sindicalismo. E acabou socializando mais ainda [...]” (CAMPOS, 1985b, p. 13), perdendo, assim, a chance de alcançar o formato político ideal do capitalismo democrático. Esse teria sido alcançado pelo Chile, o qual Campos usava de exemplo, já que a partir de um "autoritarismo liberal" conseguiu promover reformas que propiciaram o

15 Perez (1999) separa o pensamento de Campos em duas fases, a razão do Estado (1950-1975) e a razão do mercado (1982-1995). Já Ganem (2000) afirma que “[...] as décadas de 70 e 80 assistirão, no entanto, sua mudança de perspectiva, seu encantamento pelo discurso ultraliberal e, portanto, pela superação da ideia do planejamento como instrumento eficiente para combater desequilíbrios da economia [...]" (GANEM, 2000, p. 29). 
desenvolvimento econômico, desenvolvimento esse que gerou o avanço desejado na educação e uma demanda pela liberalização política.

É possível notar uma evolução no pensamento de Campos quanto às necessidades e funções do autoritarismo. No início, sua justificativa repousava em, de um lado, manter uma "disciplina social" que estava sendo perdida e que, provavelmente, seria destruída com um autoritarismo de esquerda que Goulart instauraria e, de outro, na necessidade de modernização e construção da nacionalidade, que seriam amparadas pelo regime militar, que parecia mais bem estruturado que as outras instituições existentes no Brasil para exercer tal dever.

Com o passar do tempo seu discurso foi se alterando; começou a embasar-se em que o autoritarismo de esquerda não era "biodegradável" e, por isso, era necessário que o regime militar interviesse naquele momento para que no futuro houvesse a restauração da liberdade. A necessidade da junção da democracia e a economia de mercado se tornaram cada vez mais enfáticas por Campos, julgando, como exposto, a redemocratização no Brasil como uma "democracia desperdiçada" já que havia tornado o Brasil mais "socializado" que antes, ao invés de alcançar o formato ideal do capitalismo democrático, ideal que o Chile teria alcançado, sendo usado por Campos como exemplo. Portanto, os argumentos de Campos parecem, com o passar do tempo, convergir aos de Hayek, fato corroborado pelo discurso de Campos na Constituinte, na qual buscou expor aos seus colegas a necessidade da limitação da democracia.

Assim, parece razoável afirmar que o presente trabalho apresenta um caso da difusão internacional do pensamento econômico. Houve uma transmissão de ideias de Hayek para Campos, não só influenciando sua descrença quanto ao planejamento governamental, mas também suas justificativas para um regime autoritário. Pode-se atribuir tal disseminação tanto ao modelo do contágio, quanto ao modelo da teoria da informação, ambos apresentados na seção 2 .

O modelo do contágio, por mais simplista que possa parecer, como Silva (2016) pontua, parece pertinente em tal situação, já que, de certa forma, há passividade do contaminado (Campos). A ideia da necessidade, em determinadas ocasiões, de um regime autoritário era um tema debatido na época, assim a "doença estava no ar" e, com a proximidade de Campos do debate que Hayek estava travando no Times de Londres, é razoável que se levante a hipótese de que Campos foi contaminado.

Já caso se tenha em mente o modelo da teoria da informação, é possível imaginar que Hayek seria a fonte da informação, Campos, o receptor e Gudin e Londres, os canais de transmissão para que Campos obtivesse/retivesse as informações. Ele as trazia ao cenário brasileiro por meio de jornais como o Estado de São Paulo e O Globo, enquanto residia em Londres. Após sua volta ao Brasil, fez isso também como senador e deputado federal, além de seus diversos livros publicados durante o período em que propagou as ideias hayekianas. 
O presente trabalho buscou, para explicar a evolução no pensamento de Roberto Campos, um fato que parece ter sido ignorado nos trabalhos existentes sobre o tema: o jantar com Hayek e as cartas enviadas ao The Times. Assim, espera-se ter auxiliado para o entendimento da evolução do pensamento de Roberto Campos, contribuindo, dessa forma, com o estudo da história do pensamento econômico brasileiro.

\section{REFERÊNCIAS}

BARBIERI, F. História do debate do cálculo econômico socialista. São Paulo: Instituto Ludwig Von Mises Brasil, 2013.

BIELSCHOWSKY, R. Pensamento econômico brasileiro: o ciclo ideológico do desenvolvimentismo. 5. ed. Rio de Janeiro: Contraponto, 2000.

BRASIL. Diário da Assembleia Nacional Constituinte, n. 112, 2 ago., p.458, 1987. Suplemento.

BRUZZI CURI, L. F.; CUNHA, A. M. Redimensionando a contribuição de Roberto Simonsen à controvérsia do planejamento (1944-1945). America Latina en la Historía Económica, v. 22, p. 76-107, 2015.

BRUZZI CURI, L. F.; LIMA, D. B. M. Roberto Simonsen and the Brazil-U.S. Trade Agreement of 1935: economic ideas and political action. Nova Economia, v. 25, n. 3, p. 477-500, 2015.

BURCZAK, T. Dictating Liberty. Review of Political Economy, v. 26, n. 3, p. 368-371, 2014.

CALDWELL, B.; MONTES, L. Friedrich Hayek and his visits to Chile. The Review of Austrian Economics, v. 28, n. 3, p. 261-309, 2015.

CAMPOS, R. A moeda, o governo e o tempo. Rio de Janeiro: APEC, 1964.

CAMPOS, R. O bovarismo político, a fúria legiferante et caterva (I). In: CAMPOS, R. Do outro lado da cerca. Rio de Janeiro: APEC, 1967a.

CAMPOS, R. A herança amarga (I). In: CAMPOS, R. Do outro lado da cerca. Rio de Janeiro: APEC, 1967b.

CAMPOS, R. Do outro lado da cerca. Rio de Janeiro: APEC, 1967c.

CAMPOS, R. Os militares e a política (I). In: CAMPOS, R. Ensaios contra a maré. Rio de Janeiro: APEC, 1969a.

CAMPOS, R. Ensaios contra a maré. Rio de Janeiro: APEC, 1969b.

CAMPOS, R. A opção política brasileira. In: SIMONSEN M. H.; CAMPOS, R. A nova economia brasileira. 2. ed. Rio de Janeiro: J. Olympio, 1974.

CAMPOS, R. A nova ordem econômica internacional: aspirações e realidade. In: CAMPOS, R. Além do cotidiano. 2. ed. Rio de Janeiro: Record, 1985a. 
CAMPOS, R. Além do cotidiano. 2. ed. Rio de Janeiro: Record, 1985b.

CAMPOS, R. Episódios históricos da revolução brasileira (I): os falsos dilemas (1964-1974). In: CAMPOS, R. Ensaios imprudentes. Rio de Janeiro: Record, 1987a.

CAMPOS, R. O refluxo da onda. In: CAMPOS, R. Ensaios imprudentes. Rio de Janeiro: Record, 1987b.

CAMPOS, R. Ensaios imprudentes. Rio de Janeiro: Record, 1987c.

CAMPOS, R. A fadiga dos impasses. In: CAMPOS, R. Um guia para os perplexos. Rio de Janeiro: APEC, 1988a.

CAMPOS, R. Os anos experimentais. In: CAMPOS, R. Um guia para os perplexos. Rio de Janeiro: APEC, 1988b..

CAMPOS, R. Um guia para os perplexos. Rio de Janeiro: APEC, 1988c.

CAMPOS, R. O futuro do capitalismo democrático. In: CAMPOS, R. O século esquisito. Rio de Janeiro: Topbooks, 1990a.

CAMPOS, R. O século esquisito. Rio de Janeiro: Topbooks, 1990b.

CAMPOS, R. Os três mundos revisitados. In: CAMPOS, R. Reflexões do crepúsculo. Rio de Janeiro: Topbooks, 1991.p. 85-86.

CAMPOS, R. A lanterna na popa. Rio de Janeiro: Topbooks, 1994a. .

CAMPOS, R. Prefácio. In: HAYEK, F. A. O caminho da servidão. Rio de Janeiro: Biblioteca do Exército, 1994b.

CAMPOS, R. Da necessidade de autocrítica. In: CAMPOS, R. Antologia do bom senso. Rio de Janeiro: Topbooks, 1996a..

CAMPOS, R. Pingos nos Is... In: CAMPOS, R. Antologia do bom senso. Rio de Janeiro: Topbooks, 1996b.

CAMPOS, R. A geléia filantrópica. In: CAMPOS, R. Antologia do bom senso. Rio de Janeiro: Topbooks, 1996c.

CAMPOS, R. Antologia do bom senso. Rio de Janeiro: Topbooks, $1996 \mathrm{e}$.

CARDOSO, J. L. Reflexões periféricas sobre a difusão internacional do pensamento econômico. Nova Economia, v. 19, n. 2, p. 251-265, 2009.

CAVALIERI, M. A. R.; CURADO, M. L. As influências norte-americanas de Roberto Simonsen: controle social, institucionalismo e planejamento. Estudos Econômicos, v. 46, p. 409-438, 2016. 
COATS, A. W.; COLANDER, D. C. An introduction to the spread of economic ideas. In: COLANDER, D. C.; COATS, A. W. The spread of economic ideas. Cambridge: Cambridge University Press, 1989.

DELFIM NETTO, A. Ok, Roberto Campos, você venceu! Folha de S. Paulo, 2001. Disponível em: http://www1.folha.uol.com.br/fsp/brasil/fc1010200127.htm. Acesso em: 24 mar. 2018.

FARRANT, A.; MCPHAIL, E. Can a dictator turn a constitution into a can-opener? F. A. Hayek and the alchemy of transitional dictatorship in Chile. Review of Political Economy, v. 26, n. 3, p. 331-348, 2014.

GANEM, A. A defesa do mercado no Brasil: o pensamento apologético de Roberto Campos. Nova Economia, v. 10, n. 1, p. 19-38, 2000.

GODOI, B. B. C. O projeto mais liberal de Roberto Campos. Revista de Economia Política e História Econômica, v. 19, p. 136-172, 2009.

HAYEK, F. A. Dangers to personal liberty. The Times, p. 15, July 1978a.

HAYEK, F. A. Freedom of choice. The Times, p. 15, Aug. 1978b.

HAYEK, F. A. Friedrich von Hayek: lider y maestro del liberalismo economico, El Mercurio, p. D8-D9, 1981a.

HAYEK, F. A. Friedrich von Hayek: de la servidumbre a la libertad. El Mercurio, p. D1-D2, 1981b.

HAYEK, F. A. Os fundamentos da liberdade. São Paulo: Visão, 1983.

HAYEK, F. A. Direito, legislação e liberdade: uma nova formulação dos princípios liberais de justiça e economia política. São Paulo: Visão, 1985a. v. 1: Normas e ordem.

HAYEK, F. A. Direito, legislação e liberdade: uma nova formulação dos princípios liberais de justiça e economia política. São Paulo: Visão, 1985b. v. 3: A ordem política de um povo livre.

HAYEK, F. A. O caminho da servidão. Rio de Janeiro: Biblioteca do Exército, 1994.

HAYEK, F. A. New studies in philosophy, politics and economics. London: Routledge, 2008.

HAYEK, F. A. O caminho da servidão. São Paulo: Instituto Ludwig von Mises Brasil, 2010.

KNUTSEN, T. A. Should liberals sometimes prefer dictatorships to democracies? A closer look at the Hayek thesis. Democratization, v. 23, n.3, p. 375-394, 2016.

MADI, M. A. C. A vanguarda do pensamento conservador: as ideias econômicas de Roberto Campos (1917-2001). In: SZMRECSÁNYI, T.; COELHO, F. S. (Orgs.). Ensaios de história do pensamento econômico no Brasil contemporâneo. São Paulo: Atlas, 2007.

MEADOWCROFT, J.; RUGER, W. Hayek, Friedman, and Buchanan: on public life, Chile, and the relationship between liberty and democracy. Review of Political Economy, v. 26, n. 3 , p. 358-367, 2014. 
MILLER, E. F. Hayek's the constitution of liberty: an account of its argument. London: Institute of Economic Affairs, 2010.

NELL, G. The alchemy of the can opener: how an austrian economist found himself supporting dictatorial imposition of a liberal order. Review of Political Economy, v. 26, n. 3 , p. 349-357, 2014.

NIENTIEDT, D.; EKKEHARD A. K. Liberalism and democracy: a comparative reading of Eucken and Hayek. Cambridge Journal of Economics, 2015.

PEREZ, R. T. O pensamento político de Roberto Campos: da razão do Estado à razão do mercado (1950-95). Rio de Janeiro: Ed. FGV, 1999.

SANTOS, M. H. P. Roberto de Oliveira Campos: homem de ação do governo Castelo Branco. São Paulo em Perspectiva, v. 14, n. 2, p. 112-121, 2000.

SCHMITZ, A. P.; BITTENCOURT, M. V. L. O estatuto da terra no confronto do pensamento econômico: Roberto Campos versus Celso Furtado. Economia e Sociedade, v. 23, n. 3, p. 577-609, 2014.

SILVA, V. N. L. C. Economia keynesiana ou economia de keynes? Notas sobre a transmissão do ideário de Keynes no Brasil através do liuro "Princípios de Economia Monetária" de Eugênio Gudin. 2016. Dissertação (Mestrado em Desenvolvimento Econômico) - Universidade Federal do Paraná, 2016.

Recebido em: 24/03/2018.

Aceito em: 12/10/2018.

\section{(cc) BY}

